\title{
Craig Bolland
}

\section{Stylistics in the creative writing curriculum: A problem-posing approach}

\begin{abstract}
The synergies between creative writing instruction and stylistic analysis have been noted for more than a decade in the Stylistics literature - see for example Michael Burke (2010: 7; 2013), Jeremy Scott (2013a; 2013b: 99), et al - but there remain very few case studies of the implementation of such an approach. The undergraduate unit KWB211: Stylistics, taught at the Queensland University of Technology, takes a Stylistics approach to the teaching of creative writing to an undergraduate cohort, and furthermore uses the Freirean notion of problem posing as a methodological and philosophical basis for its pedagogic approach. This paper presents a case study of the content and approaches of KWB211: Stylistics. It argues that the natural synergies between the field of Stylistics and the field of Creative Writing can inform the teaching of literary technique to a cohort of undergraduate writers, and that Stylistics can be made to be a practitioner-facing example of literary theory especially when using a problem posing approach to instruction. Keywords: Stylistics, creative writing, pedagogy, problem posing, Freire
\end{abstract}

\section{Introduction}

This paper presents a problem-posing approach to teaching Stylistics as part of a creative writing curriculum. Specifically, this paper makes a case study of the unit KWB211: Stylistics, an undergraduate unit taught at the Queensland University of Technology that uses a Stylistics based approach to teaching creative writing to a cohort of undergraduate students [1].

This paper agrees with Leech and Short's definition of Stylistics, namely that 'stylistics, simply defined as the (linguistic) study of style, is rarely undertaken for its own sake, simply as an exercise in describing what use is made of language. We normally study style because we want to explain something, and in general, literary stylistics has, implicitly or explicitly, the goal of explaining the relation between language and artistic function' (Leech \& Short 2007: 11).

The paper takes its definition of problem-posing education from Paulo Freire who sees that problemposing is a vehicle for developing co-intentionality and mutual ownership of the learning process and that 'co-intentionality begins when the teacher presents a problem for enquiry related to a key aspect of student experience' (Leonard \& McLaren 2002).

The pedagogic concerns of this paper represent a contribution to ongoing discussions in both the disciplines of Creative Writing pedagogy and Pedagogical Stylistics. Creative writing journals such as TEXT and New Writing have contained a robust discussion around pedagogy since their inception, just as have Stylistics journals such as Language and Literature. The synergies between creative writing instruction and stylistic analysis have been noted for more than a decade in the Stylistics literature - see for example Michael Burke (2010: 7), Michael Burke (2013), Jeremy Scott (2013a), Jeremy Scott (2013b: 99), et al - but there remain very few case studies of the implementation of such an approach.

\section{Aims and objectives of the unit}

KWB211: Stylistics is a unit taken in the first semester of the second year of QUT's Bachelor of Fine Arts. As such, students come to the unit having studied a year of their creative writing major already. In this first year, the students will have studied eight units containing introductions to basic composition, introductions to core literary theories, some studies of different genres from youth writing to creative non-fiction, and some studies of different written forms such as non-fiction, 
fiction, poetry and scripts. Throughout this, there is a craft emphasis at a basic level, introducing students to the concerns that creative writing practitioners have with elements of fiction such as voice, dialogue, setting, character, plot, and so on. Students will have produced creative writing in all of the eight units of their first year.

The idea for KWB211: Stylistics is that it takes a problem-posing approach to deepen students' experience to date and to challenge them as writers to deliberately create aesthetic experiences for their readers. The unit does not engage with broader narrative concerns, but with how to be conscious of language use for effect. Students are asked to reflect on a series of problems that revolve around a central concern, namely 'If I want to create a certain experience for a reader, what are some ways in which language-use itself might contribute to the delivery of that experience?' This is an attempt to explicitly situate their burgeoning creative practice, and the problems arising within that practice, within the world in a Freirean pedagogic sense.

The unit is about language, notably about using Stylistics to make visible some of the ways in which language has an impact on readers. Each lecture focuses on a creative problem, a key idea from Stylistics, and some sample texts that illuminate writers using the stylistic technique. Students are then asked to take the technique/stylistic principle under discussion and use it in a piece of their own work that responds to a creative challenge they might face.

In the Week One Unit Information document which all students are given at the beginning of the course, the aims and objectives of KWB211: Stylistics are laid out as follows:

On completion of this unit you should be able to:

1. demonstrate an applied understanding of a broad range of stylistic and technical devices used in prose fiction;

2. analyse critically and engage with stylistic and technical devices used by a wide range of published authors;

3. develop and write experimental narrative, including deliberate manipulation of reader experience through critically applied technique;

4. apply techniques of rewriting and editing to both fictive and non-fiction narratives.

It is these aims and objectives that the pedagogic approach of KWB211: Stylistics seeks to serve. At the heart of meeting these aims and objectives is a problem-posing approach taken in each lecture and tutorial within the unit.

\section{Problem-posing approaches within KWB211: Stylistics}

Problem-posing education is an approach developed by Paulo Freire when working with illiterate and economically disadvantaged learners in Brazil. His seminal text, Pedagogy of the Oppressed was first published in Portuguese in 1968, and was translated into English and published in 1970. In it he sets out his critique of 'banking' education, where knowledge is transacted from an informationcontaining instructor into the empty vessels of the students, and argues for an emancipatory pedagogy that treats the student as the co-creator of the curriculum, the knowledge, and the resulting critical consciousness that emerges from the process.

One of Freire's key ideas related to the notion of problem-posing education, of locating the learning alongside the learners via the posing and unpacking of situated problems in familiar lived contexts. This notion has formed the basis of modern critical pedagogy, and has been further developed by theorists such as Henry Giroux, Roger Simon, David Livingstone, Joe Kincheloe, Peter McLaren, et al.

In 'Teaching critically as an act of praxis and resistance', Boyce (2002) summarises the four stages of problem-posing as beginning with students experiencing themselves as knowledgeable by (a) writing, (b) critically examining the knowledge in a field, (c) identifying the individual aspects and context of a problem, and (d) identifying possible actions in response.

Schleppegrell and Bowman identify that

the first step in this approach is to identify topics of concern to students. The concerns are then presented to the students through visual or linguistic input: a picture, dialogue, or other text. Criteria used for selection of this input are that it depicts a situation students can easily recognise, and that it poses a problem with several possible solutions. (Schleppegrell \& Bowman 1995: 300) 
In the spirit of this, the delivery of KWB211: Stylistics involves using a pedagogic approach that is centred around a problem presented to the student that is familiar to them as artists and that demands the student identify the key elements of the problem and their relationship to the learning outcome.

In practical terms, teaching in KWB211: Stylistics is delivered through a one-and-a-half-hour lecture and a one-and-a-half-hour tutorial each week. The lectures are delivered to the entire cohort of between 120 and 140 students. The tutorials typically hold 20-30 students.

The lectures are used to deliver a key theme from within Stylistics (for example, the idea of foregrounding, or the idea of a cline of interference in speech acts), illuminated with textual examples of the theme from writers working in various forms (fiction, non-fiction, scripts, etc). At the start of each lesson a problem is posed for the student to consider. These problems relate to issues the student is likely to encounter within their creative practice, have no clear single solution, and work to situate the topic within the lived experience of the student.

As an example of this, the first lecture in the series, which deals with the idea of foregrounding, begins with the following problem posed to the students:

As a writer, you don't want everything on the page to have the same level of salience to a reader. You want some pieces of the writing to be more resonant, more distinct, than others. Not having this would result in flat, atonal, affectless prose, empty of modulation, with the reader having no direction from you as to what is important and what is not. So how do we do this? How to we introduce this basic musicality and make one clause or sentence stand out within a paragraph? How do we make, subtly, and perhaps in a way that the reader does not consciously even recognise, one piece of text stand out from the text around it? (Bolland 2017a)

Freire argues that: 'Students, as they are increasingly posed with problems relating to themselves in the world and with the world, will feel increasingly challenged and obliged to respond to that challenge' (Freire 1997: 81). It is this relationship with themselves within the world as creative practitioners that these problems attempt to engage.

The lecture itself then becomes an exercise in unpacking the nuances of the problem, and in shining light on it via key ideas from Stylistics, illuminated by example. The narrative thread of the lecture follows this process of exploring the problem, moving from general features of the problem to the more specific.

At the end of the lecture students are asked to self-identify a problem that they are facing or might face in their own creative practice, and are directed to perform a writing exercise that explores their own individual solution to the problem using the stylistic theme for the week as part of their response. Requiring the students at the end of each lecture to engage in formulating their own problem-posing 'can help students see a standard topic in a sharper light and enable them to acquire a deeper understanding of it' (Brown \& Walter 2005: 1). That said, the students are also provided with a choice of at least three pre-designated writing exercises to engage with if they cannot formulate their own, as one issue with problem-posing learning is that students may have difficulty posing their own problems if they do not possess the conceptual or higher-order thinking skills needed to identify the key learning objectives, or to make connections between the problem and their own prior knowledge (Sung, Hwang \& Chang 2016).

These problems articulate into the tutorial spaces for the unit. Tutorials take a different format over the first half and the last half of the semester. In the first half of the semester, the tutorial consists of a tutor-led unpacking of stylistic devices within an extended reading the students have been asked to complete, followed by a discussion of the analysis the students are asked to undertake in the second half of semester, followed by the writing exercises set up in the lecture. The tutor-led unpacking is intended as a modelling exercise, skilling the students in ways to perform their own subsequent stylistic analyses. This then articulates into the tutor workshopping ideas that the students have for their own analyses, providing models for the cohort of how to undertake stylistic analyses.

In the second half of the semester, the tutor gives way to the students, and the students lead their own stylistic analyses of texts they themselves have selected. They are asked to select a text that shows a stylistic solution to a problem they have been facing in their own work - for example if their dialogue has been flat, they might choose to do an analysis of insertion sequencing or the breaking of Gricean maxims at play in another author's dialogue. They give a class presentation where they unpack the stylistic device their chosen author is using, and reflect on the impacts on themselves as readers that these devices engendered. They also show some of their own new creative work that has been influenced by their study and unpack the relationship between it and what they have just discussed. This is highly self-reflective work where the students demonstrate not just consciousness 
of a stylistic device, but consciousness of the conscious shaping of their own work in reply. It is in this half of the semester that we see most fully enacted the Freirean ideal of the student being, via problem-posing education, co-creator of the curriculum, and in particular through their possession of critical consciousness. As Freire writes,

Those truly committed to liberation must ... abandon the educational goal of deposit-making and replace it with the posing of the problems of human beings in their relations with the world. "Problem-posing" education, responding to the essence of consciousness - intentionality - rejects communiqués and embodies communication. It epitomizes the special characteristic of consciousness: being conscious of, not only as intent on objects but turned in upon itself in a Jasperian "split" - consciousness as consciousness of consciousness. (Freire 1997: 60)

For assessment purposes, the students are asked to hand in a portfolio of their exercises mid semester and again at the end of semester. In each portfolio they are asked to identify just one of the exercises as the exercise on which they want to be assessed. This allows them to 'fail' or 'make mistakes' in the majority of their exercises, and as such to hopefully stretch and experiment as writers. It is framed to them in this way - that the exercises are spaces for literary play, and that they only need to get one piece 'right' before handing in their portfolio. Students are also allowed to edit or polish or rework the piece that they want assessed.

With each portfolio submission they are also asked to write a rationale, which is assessed alongside their nominated piece of creative work. In this rationale, the student is asked to detail the problem they set for themselves and the goal of their writing exercise and to discuss how they used a stylistic device as part of their creative work in response to the problem. This involves them demonstrating an understanding of the technicalities of the stylistic device they have chosen, as well as demonstrating how, as artists, they are consciously adapting that device into their own voice and creative practice.

\section{The unit in action}

To help concretise the discussion to this point, I will now go on to discuss in detail two of the weekly activities (lectures and tutorials) for the unit. These are: a week that looks at foregrounding (the first lecture in the series); and a week that looks at the cline of narrative interference proposed by Leech and Short (2007) as it relates to speech acts, a lecture that comes a little after midway through the unit.

Foregrounding is the first stylistic concept that students are given, and the lecture is introduced as described earlier by way of a writerly problem as expressed earlier.

The students are then given three texts to consider, and are asked 'what do these three things have in common?' The first is the poem 'The Lost Art of Letter Writing' by Eavan Boland (Boland 2014). The second is a box of Snax Crackers. The third text is a video clip of the British entertainer Derren Brown where, through use of conversational hypnosis, he convinces the actor Simon Pegg that he wanted a BMX bike for his birthday (Brown 2015).

We then as a class discuss each of the three cases individually. In 'The Lost Art of Letter Writing', Boland undermines expectations the text establishes through variations in the text. On the box of crackers, the brand name is derived from a misspelling of the word 'Snacks' and design elements are intended to stand out off the shelf. In the Derren Brown segment, he makes use of linguistic patterning and speech emphasis to call subtle attention to certain words as they are used, making them gradually more and more salient to his listener, at a level of consciousness the listener themselves is not aware of.

After this, the notion of foregrounding is introduced to the students. This is done via a brief history of the idea, tracing it from the Russian Formalists to the Prague Structuralists and through to definitions given by Mukařovský and the notion that foregrounding is a way of disrupting everyday communication enabling literature to present meanings with an intricacy that everyday language does not typically allow. The idea that foregrounding works by a mechanism of 'making strange' is introduced.

The key idea that art works on perception as its canvas, and that foregrounding can serve to slow down or make more dense the act of perception is then introduced via Shklovsky who writes in his seminal essay 'Art as a Device':

The purpose of art is to impart the sensation of things as they are perceived and not as they are known. The technique of art is to make objects unfamiliar to make forms difficult to increase the difficulty and length of perception, because 
the process of perception is an aesthetic end in itself and must be prolonged. Art is a way for experiencing the artfulness of an object, the object is not important. (Shklovsky 2016: 64)

A phenomenon is then introduced, namely that discovered by Emy Koopman around literariness and empathy. Koopman (2016) gave readers one of three different versions of the novel Counterpoint by Anna Enquist. The first version of this was the original, which contained significant use of foregrounding at semantic, phonetic and grammatical levels. The second version given was a rewritten version where imagery was removed. The third version was a rewritten version where all instances of foregrounding were removed. Koopman found that people who read the original version scored higher on metrics around self-reported empathy than people who read the non-foregrounded version. Interestingly, readers who encountered the original version were also able to report having experienced more ambivalent and nuanced emotions than those who read the third, non-foregrounded version of the text. What is it, the students are asked to consider, about foregrounding that results in a more empathic response from readers?

The idea that foregrounding can be achieved through linguistic deviation is now introduced and examples of this are given from prose extracts. In one extract we analyse the opening paragraphs of Cormac McCarthy's No Country For Old Men, looking at how the narrator's second-guessing of himself serves to break the pattern of reporting in the rest of the paragraphs. We also look at extracts from George Saunder's Sea Oak looking at various types of foregrounding used in the story.

At this point, we have a more technical discussion on the kinds of linguistic deviation that writers can use in order to foreground - phonological, graphological, and so on.

The issue of foregrounding is here made explicitly practitioner-facing with the kinds of deviation listed being grounded in ideas of how and why a writer might choose to work with this kind of deviation. The discussion here is intended to be generative for the class of creative writing students, to give them fresh ideas about ways in which they might stretch or challenge their own existing writing practices by consciously using foregrounding strategies.

By way of a conclusion to the lecture, the students are now asked to pose their own problem and see if they can write a creative solution to it. Their homework for the week is to consider how foregrounding might help them to solve this problem in their own creative work, and to write 1000 words of creative work that uses foregrounding at several points by means of stylistic deviation in order to solve that problem.

In the tutorials for this week, four readings are given. They are extracts from No Country for Old Men by Cormac McCarthy, The Picture of Dorian Grey by Oscar Wilde, The Adventures of Holly White and the Incredible Sex Machine by Krissy Kneen, and The Cold Six Thousand by James Ellroy.

The tutorials revolve around unpacking the mechanics of voice in each of these very differently voiced stories, and then looking at instances where the authors play against their established voices in order to foreground moments or objects. As this is the start of semester, a discussion is also had in the tutorial about Barthes' 'The Death of the Author' - asking the question of how much influence can the creative writing students in the class expect to exert on their readers via their skilful use of language. There is then time given to students writing their weekly homework, with a further discussion of foregrounding taking place in so far as it relates to individual student's questions as they write.

The next week of instruction I will look at in this paper is entitled Speech, Narrative and Mediation. This week falls a little after mid-way through the course, in week eight of the semester. Prior to this, students have had another lecture on speech and dialogue and key ideas from Stylistics, such as insertion sequencing, Gricean maxims and so on. Speech, Narrative and Mediation therefore is intended to ground out their understanding of key ideas from Stylistics as they relate to literary dialogue. It is in essence a lecture on different types of speech acts and the aesthetic implications of each for creative writing students. This lecture borrows heavily on ideas as expressed in chapter 10 of Style in Fiction (2nd edition) by Leech and Short (2007). An acknowledgement to this effect is made at the start of the lecture and in lecture materials. Style in Fiction was previously set as a textbook for this unit, but as it far exceeds the scope and range of the unit was subsequently removed.

The lecture starts with the following problem posed to the students:

You are editing a piece of your own work and have realised that one of the major conversations in it has the characteristics of a tennis match. One character says something, the other character replies, and so it goes. Looking further through 
the work you notice that you tend to have a certain sameness to the way you are doing dialogue - everything is in direct speech with a "he said /she said / John shouted / Mary whispered" approach. How can you expand your reach here? What are some of the other ways you can represent speech and what are the impacts of so doing? (Bolland 2017b)

As with all of the problems posed, a brief discussion follows with the students sharing some ideas on how they might creatively respond to that problem. This then leads into a discussion of what direct speech is, with examples. Students are shown that the speech and reporting clauses are clearly distinct from each other - that the character and the narrator are operating independently. It is noted that for writers this allows for interesting effects. Students are asked to consider the difference between the two sentences:

'I love you,' she said.

'I love you,' she lied.

And to note the extent to which the narrator is helping to mediate the meaning of what the character has directly said via the reporting clause.

The class is then stepped through a reading of the first two pages of George Saunders' short story 'Victory Lap' (Saunders 2009). They are asked to pay attention to all the different types of speech reporting that go on in this extract that are not direct speech or direct thought. Saunders often writes a third person voice that is closely focalised to the thoughts and feelings of the character being followed. This results in many different types of speech act that go beyond the direct.

Students are then shown an example of Cormac McCarthy's The Road(2010) as it stands in the original, namely:

The road was empty. Below in the little valley the still gray serpentine of a river. Motionless and precise. Along the shore a burden of dead reeds. Are you okay? he said. The boy nodded. Then they set out along the blacktop in the gunmetal light, shuffling through the ash, each the other's world entire.

They crossed the river by an old concrete bridge and a few miles on they came upon a roadside gas station. They stood in the road and studied it. I think we should check it out, the man said. Take a look. The weeds they forded fell to dust about them. They crossed the broken asphalt apron and found the tank for the pumps. The cap was gone and the man dropped to his elbows to smell the pipe but the odor of gas was only a rumor, faint and stale. He stood and looked over the building. The pumps standing with their hoses oddly still in place. The windows intact. (McCarthy 2010: 172)

They are then shown how this example would look if rewritten into conventionally formatted direct speech, as follows:

The road was empty. Below in the little valley the still gray serpentine of a river. Motionless and precise. Along the shore a burden of dead reeds.

'Are you okay?' he said. The boy nodded. Then they set out along the blacktop in the gunmetal light, shuffling through the ash, each the other's world entire.

They crossed the river by an old concrete bridge and a few miles on they came upon a roadside gas station. They stood in the road and studied it.

'I think we should check it out,' the man said. 'Take a look.'

The weeds they forded fell to dust about them. They crossed the broken asphalt apron and found the tank for the pumps. The cap was gone and the man dropped to his elbows to smell the pipe but the odor of gas was only a rumor, faint and stale. He stood and looked over the building. The pumps standing with their hoses oddly still in place. The windows intact. (Bolland 2017b)

They are asked to analyse the very different aesthetic impact the rewritten version has from the original.

Finally, an example from James Joyce's Ulysses is given noting the many similarities between how McCarthy and Joyce use speech acts other than the direct.

This then raises the question - what other kinds of speech act exist apart from direct speech, and what are the aesthetic impacts of those acts? 
Students are at this point introduced to the idea of the narrator's cline of interference as proposed by Leech and Short (2007) and shown the diagram of this from Style In Fiction as follows:

\section{Cline of 'interference' in report}

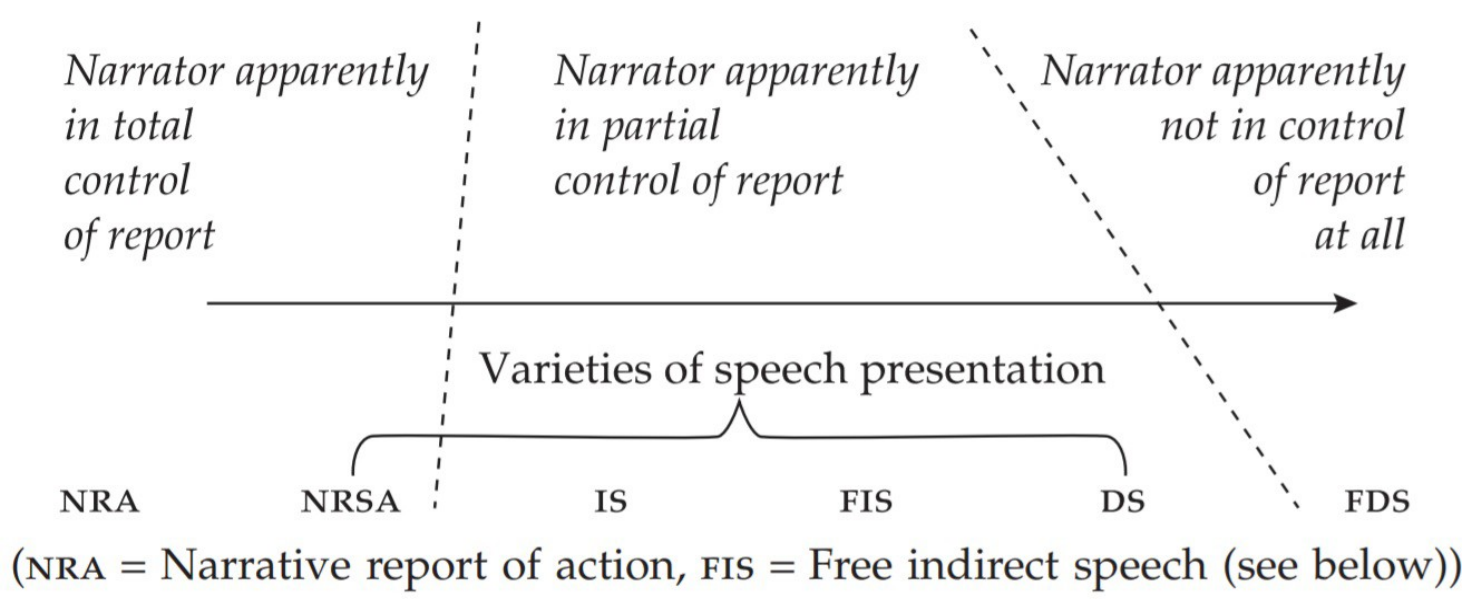

(Leech \& Short 2007: 260)

This diagram lays out the cline of narrative reporting of action / narrative report of speech act / indirect speech / free indirect speech / direct speech / free direct speech. It is explained that the narrator is entirely mediating the representation of speech (ie there is no necessary equivalence between what the character was saying and what the narrator is reporting) at the narrative reporting of speech act end of the cline, whereas the narrator is not at all mediating the representation of speech (ie there is perfect equivalence) at the free direct speech end of the cline.

The students are then stepped through this idea in detail - that as creative writers at times their narrators will be mediating between what a character is saying and what the reader is getting more so than others, and that this offers different types of speech act a number of different aesthetic impacts.

Indirect speech is the next speech act examined with the differences between this and direct speech noted (quotation marks are removed, first and second person pronouns shift to third person, tense backshifts, proximal adverbs become distal, etc). Students are asked to consider what the differences in aesthetic function this might provide are, as the content of the speech becomes more subordinate to the act of speaking and the narrator assumes a greater mediating role.

The notion of equivalence is further unpacked here. Because indirect speech has less equivalence to the actual utterance than direct speech, it becomes unreliable if the narrator is unreliable and there is the potential for creative writers to work with this. It is more distant from the utterance and therefore could be used to show an emotional relationship to the speech being reported. If a narrator is uncomfortable in recounting the particulars of a speech utterance, for example, indirect speech might reflect that cognitive relationship. Students are asked to consider the following example:

'What the hell are you playing at?' John said. 'Why would you let that happen? What kind of coward are you?'

'I ... I just froze. I wasn't thinking.'

John told me I was weak.

I didn't protest.

John circled me and told me. He counted the ways. He paced his circle and he ranted.

I lowered my eyes and heard it all. (Bolland 2017b)

In this example, the narrator assumes more mediation of the speech as they grow more distressed at recalling and reporting the events and as such seek to escape direct equivalence; the narrator takes the reader further away from the actual speech itself as their distress grows and they dissociate. This short passage spans almost the entire cline identified by Leech and Short, landing on an instance of narrative reporting of action.

Narrative reporting of speech acts is the next type examined; note that this is not an exercise in just moving from one type of speech act to another along the cline but rather in creating a narrative 
around distinct aesthetic impacts. It is explained that here the narrator is in control of what is being reported, and equivalence is entirely lost. The speech act is being reported on par with other kinds of narrative reports of action. It is noted that the uses of this might be because a summary is called for or that the content of the speech itself is not important. It is again brought to the students' attention that this might be used because of a narrator's emotional relationship to the speech act being described, or because an unreliable narrator is deliberately manipulating what is being reported.

At this point the diagram of the cline of interference is again presented and the students are oriented to the types of speech act that have so far been discussed and the ones that remain to be discussed.

Free indirect speech is now turned to and defined. Students are asked to share ideas about what the aesthetic and other characteristics of this kind of speech act are, and why a writer might choose to report a speech act in free indirect speech.

Once the students have had a chance to reach and share their own conclusions, the technical aspects of free indirect speech are unpacked. Technicalities are discussed such as that the tense and pronoun use are the same as with indirect speech, that this usually occurs in the context of a narrative report, that indirect speech is often used as a way of sliding into free indirect speech, that there is generally no reporting clause in free indirect speech and that it retains some of the qualities of direct speech such as vocatives and direct questions.

Some of the aesthetic implications are now discussed, including the possibility for irony here, and how this speech act supresses one side of a conversation with only the narrator and speaking character's viewpoints being described. It is noted that these can be collapsed in the instance of first person narration and an example of free indirect speech from Nabokov's Lolita is unpacked showing the large potential that suppressing one side of a conversation has for writers in presenting a biased and unreliable perspective of a conversation:

Hardly had the Farlows gone than a blue-chinned cleric called - and I tried to make the interview as brief as was consistent with neither hurting his feelings nor arousing his doubts. Yes, I would devote all my life to the child's welfare. Here, incidentally was a cross that Charlotte Becker had given me when we were both young. I had a female cousin, a respectable spinster in New York. There we would find a good private school for Dolly. Oh, what a crafty Humbert!

(Nabokov as cited in Leech \& Short 2007: 264)

The final speech act, free direct speech, is now addressed.

Students are asked to discuss what some of the characteristics and aesthetics of this are. The discussion proceeds then as it did with free indirect speech. The idea of free direct speech being the end of the cline where the narrator has no mediating role and perfect equivalence between what the characters are saying and what is reported on the page is addressed and some of the aesthetics of this unpacked. Hemingway is used as the exemplar throughout.

The discussion now moves to show some examples of speech acts that are more complex. A passage of Joyce's Ulysses that merges narrative reporting of action and free direct speech without morphological or graphological markers to indicate switches between the two is given:

By Brady's cottages a boy for the skins lolled, his bucket of offal linked, smoking a chewed fag butt. A smaller girl with scars of eczema on her forehead eyed him, listlessly holding her battered caskhoop. Tell him if he smokes he won't grow. O let him! His life isn't such a bed of roses! Waiting outside pubs to bring da home. Come home to ma, da. Slack hour: won't be many there. He crossed Townsend street, passed the frowning face of Bethel. El, yes: house of: Aleph, Beth. And past Nichols' the undertaker's. At eleven it is. Time enough. (Joyce 1992: 18)

This passage is discussed, together with the readerly impacts this has. This is compared again to a very similar use in McCarthy's The Road. The impacts of the choice to remove distinctions between narrative and speech are discussed.

Free indirect thought and free direct thought are now discussed, with notes on how pronouns are used differently within each. An extract from Jonathan Franzen's The Corrections is used to illustrate the differences and a discussion on why a writer might choose these approaches is held. The example given is:

It seemed as if, in every motel he stayed in, he had neighbors who fornicated like there was no tomorrow - men of ill-breeding and poor discipline, women who chuckled and screamed. At 1 a.m. in Erie, Pennsylvania, a girl in the next room 
ranted and panted like a strumpet. Some slick, worthless fellow having his way with her. Alfred blamed the girl for taking it easy. He blamed the man for his easygoing confidence. He blamed both of them for lacking the consideration to keep their voices down. How could they never once stop to think of their neighbor, lying awake in the next room? He blamed God for allowing such people to exist. He blamed democracy for inflicting them on him. He blamed the motel's architect for trusting a single layer of cinder block to preserve the repose of paying customers. He blamed the motel management for not keeping in reserve a room for guests who suffered. He blamed the frivolous, easygoing people of Washington, Pennsylvania, who had driven 150 miles for a highschool football championship game and filled every motel in northwest Pennsylvania. He blamed his fellow guests for their indifference to the fornication, he blamed all of humanity for its insensitivity, and it was so unfair. It was unfair that the world could be so inconsiderate to a man who was so considerate to the world. (Franzen 2004: 51)

The potential of free direct thought and free indirect thought to be used to enmesh a character's intrapsychic world with the external world, creating an aesthetic that has simultaneous characteristics of both first and third person narration, is discussed as are the opportunities this presents to the creative writer. Again, it is the discussion of the possibilities the stylistic approach offers to creative writers that is the chief concern here, pivoting Stylistics to be firmly practitioner-facing.

One final example is given - an extract from McCarthy's The Road, showing a passage where it is impossible to tell if the sentence beginning 'In the nights...' is a speech/thought act or narration, and what a powerful effect this has as the landscape and the characters merge and bleed one into the other.

He stood in the doorway to his room. A small space under the eaves. This is where I used to sleep. My cot was against this wall. In the nights in their thousands to dream the dreams of a child's imaginings, worlds rich or fearful such as might offer themselves but never the one to be. He pushed open the closet door half expecting to find his childhood things. Raw cold daylight fell through from the roof. Gray as his heart. (McCarthy 2010: 23)

This demonstrates how an innovative approach to reporting speech acts can be a powerful vocal tool for a writer. Students are asked to consider how, in instances where they are wanting to demonstrate a strong relationship between place and character, approaches such as this might be of use to them.

By way of a conclusion to the lecture, the students are now asked to pose their own problem and see if they can write a creative solution to it. As a writer do they have a 'default' kind of speech act in their work, and are there others they underutilise? Is there some element of dialogue within their creative work that might be improved upon by using different varieties of speech acts? Is there some other writerly problem that they are facing that clever deployment of different kinds of speech act might be a solution to?

Their homework for the week is to consider this problem within their own creative practice that might be solved by a more deliberate use of speech acts, and to write 1000 words of creative work that uses a wide variety of different speech acts for considered aesthetic impact in order to solve that problem.

As this week takes place in the second half of the semester, the tutorial time is taken up by students leading their own stylistic analyses of texts of their choice for the first half of the tutorial. There is then time given to students writing their weekly homework, with a further discussion of speech acts taking place in response to individual student's questions as they write.

As can be seen in these examples, KWB211: Stylistics takes a practitioner-facing approach to Stylistics. Part of this approach comes via problem posing within a creative practice frame. In making Stylistics practitioner-facing, once students are introduced to the impacts and influences that certain stylistic devices have, it is a natural progression to challenge them to use these to inflect their own creative work.

Stylistics is a natural choice for a practitioner-facing approach because it already has as a concern the reading experience and the impacts that language has on reading. It is a relatively small step to take the emphasis on reading to being about creating reading experiences and therefore being about writing.

\section{Conclusion}


Horn (2002) makes the point that the role of the scholar-practitioner is to use practice as a site for testing theory while including student-practitioners as partners in theory development. $K W B 211$ : Stylistics is intended for a student cohort of aspiring creative practitioners and as such represents an attempt to deploy Stylistics in a practitioner-facing way, a way that uses practice as a site for developing and testing theory as well as a site where practice is deeply informed by theory. It does this by emphasising the impacts and aesthetics of different stylistic devices, and emphasising generative ideas of how students might adopt these within their own work. It adopts a problemposing approach to challenging students to think about ways in which stylistic notions might be synthesised into their own creative practice.

\section{Notes}

[1] QUT uses the term 'unit' to refer to what other institutions might term subjects or modules etc. return to text

\section{Works cited}

Boland, E 2014 'The Lost Art of Letter Writing', The New Yorker (August 25):

https://www.newyorker.com/magazine/2014/08/25/the-lost-art-of-letter-writing (accessed 21 April 2017) return to text

Bolland, C 2017a Lecture 1: Foregrounding [Powerpoint Slides], Queensland University of Technology, KWB211 Stylistics Blackboard: https://blackboard.qut.edu.au/ (access is restricted to enrolled students) return to text

Bolland, C 2017b Lecture 8: Speech Acts [Powerpoint Slides], Queensland University of Technology, KWB211 Stylistics Blackboard: https://blackboard.qut.edu.au/ (access is restricted to enrolled students) return to text

Boyce, ME 2002 'Teaching critically as an act of praxis and resistance', Electronic Journal of Radical Organization Theory 2, 2: http://www.mngt.waikato.ac.nz/ejrot/Vol2_2/boyce.pdf (accessed 21 April 2017) return to text

Brown, D (Producer) 2015 'How To Hypnotise Simon Pegg - Derren Brown', YouTube: https://www.youtube.com/watch?v=sEmCQzueyEQ (accessed 21 April 2017) return to text

Brown, SI \& MI Walter 2005 The art of problem posing, Lawrence Erlbaum, Mahwah NJ return to text

Burke, M 2010 'Why care about pedagogical stylistics?' Language and Literature 19, 1: 7-11:

http://journals.sagepub.com/doi/abs/10.1177/0963947009356805 (accessed 21 April 2017) return to text

Burke, M 2013 'Systemic Stylistics: An Integrative, Rhetorical Method of Teaching and Learning in the Stylistics Classroom', in M Burke, S Csabi, L Week \& J Zerkowitz (eds), Pedagogical Stylistics: Current Trends in Language, Literature and ELT, Bloomsbury, London: 77-95 return to text

Franzen, J 2004 The Corrections, St Martin’s Press, New York return to text

Freire, P 1997 Pedagogy of the Oppressed: Revised 20th-Anniversary Edition, Continuum, New York return to text

Horn, RA 2002 'Differing perspectives on the magic of a dialogue: Implications for a scholar-practitioner leader', Scholar-Practitioner Quarterly 1: 83-102 return to text

Joyce, J 1992 [1922] Ulysses, Everyman, London return to text

Koopman, E 2016 'Effects of "literariness" on emotions and on empathy and reflection after reading', Psychology of Aesthetics, Creativity, and the Arts 10: 82-98 return to text

Leech, G \& M Short 2007 Style In Fiction: A Linguistic Introduction to English Fictional Prose (2nd edn), Pearson Education, Harlow return to text

Leonard, P \& P McLaren 2002 Paulo Freire: A Critical Encounter, Routledge, Oxford return to text

McCarthy, C 2010 The Road, Pan Macmillan, London return to text

Saunders, G 2009 'Victory Lap', The New Yorker (October 5):

https://www.newyorker.com/magazine/2009/10/05/victory-lap (accessed 21 April 2017) return to text

Schleppegrell, MJ \& B Bowman 1995 'Problem-posing: a tool for curriculum renewal', ELT Journal 49, 4: 297-307 return to text

Scott, J 2013a Creative Writing and Stylistics, Palgrave, London return to text

Scott, J 2013b ‘Creative Writing: A Stylistics Approach', in M Burke, S Csabi, L Week \& J Zerkowitz (eds),

Pedagogical Stylistics: Current Trends in Language, Literature and ELT, Bloomsbury, London: 96-112 return to text

Shklovsky, V 2016 Viktor Shklovsky: A Reader (ed A Berlina), Bloomsbury, London return to text 
Sung, H-Y, G-J Hwang \& Y-C Chang 2016 'Development of a mobile learning system based on a collaborative problemposing strategy', Interactive Learning Environments 24, 3: 456-471 return to text

Craig Bolland is a playwright, filmmaker and novelist and lectures in Creative Writing at the Queensland University of Technology. His current research interests are in the intersections between psychology and fiction, and in how Stylistics (notably Text World Theory) can be used to understand readers' empathic responses to fiction.

\section{TEXT}

Vol 21 No 2 October 2017

http://www.textjournal.com.au

General Editor: Nigel Krauth. Editors: Kevin Brophy, Enza Gandolfo \& Julienne van Loon text@textjournal.com.au 